\title{
PERSEPSI KONSUMEN TERHADAP HASIL PRODUKSI BUAH BELIMBING DARI DESA WARINGINSARI KECAMATAN LANGENSARI KOTA BANJAR
}

\author{
ASEP TOPIK ${ }^{1}$, TRISNA NOOR INSAN ${ }^{2}$, MUHAMAD NURDIN YUSUF ${ }^{1}$ \\ ${ }^{1}$ Fakultas Pertanian Universitas Galuh \\ ${ }^{2}$ Fakultas Pertanian Universitas Padjajaran \\ *Email : aseptaopik454@gmail.com
}

\begin{abstract}
ABSTRAK
Penelitian ini bertujuan untuk mengetahui 1) Persepsi konsumen terhadap buah belimbing di Desa Waringinsari Kecamatan Langensari di Kota Banjar. 2) Persepsi konsumen terhadap harga belimbing di Desa Waringinsari Kecamatan Langensari di Kota Banjar. 3) Persepsi konsumen terhadap promosi belimbing di Desa Waringinsari Kecamatan Langensari di Kota Banjar. Jenis penelitian yang digunakan adalah kualitatif dengan metode survei. Teknik pengambilan sampel menggunakan Accidental Sampling. Menurut sugiyono (2009), Accidental Sampling adalah teknik penentuan sampel berdasarkan kebetulan, yaitu konsumen yang secara kebetulan/insidental bertemu dengan peneliti dapat digunakan sebagai sampel dengan jumlah responden 40 orang. Hasil penelitian menunjukkan bahwa Tingkat pengaruh konsumen dalam keputusan pembelian buah belimbing di Desa Waringinsari tergolong ke dalam kategori sedang. Tingkat pengaruh jika dilihat per dimensi yaitu : a). Dimensi produk memiliki tingkat pengaruh baik. b). Dimensi harga memiliki tingkat pengaruh sedang. c). Dimensi promosi memiliki tingkat pengaruh sedang. Kendala yang dihadapi dalam melakukan kegiatan pengambilan keputusan pembelian belimbng di Desa Waringinsari yaitu : a). Kendala internal ; Kendala yang dihadapi responden dalam pengambilan keputusan pembelian belimbing di Desa Waringinsari dilihat dari aspek internal disebabkan karena pengalaman belajar dan memori dalam membeli buah belimbing, dimana dimensi harga menjadi kendala, karena harganya tidak berbeda jauh dengan harga belimbing di pasar tradisional, namun konsumen yang membeli ke Desa Waringinsari akan mendapatkan gratis makan sepuasnya belimbing yang ada di kebun degan syarat dimakan ditempat (di kebun belimbingnya), akan tetapi dengan ukuran belimbing yang besar, sehingga konsumen tidak banyak menghabiskan belimbing di kebun belimbing di Desa Waringinsari. b) Kendala Eksternal ; Kendala pada keputusan pembelian dilihat dari aspek eksternal disebabkan faktor sosial yaitu kelompok referensi dan keluarga. Sebagian kecil responden mengatakan bahwa mereka mendapat informasi melalui keluarga bahkan kerabat tentang referensi untuk membeli belimbing yaitu di pasar tradisonal, dengan alasan harga yang lebih murah meskipun produk di bawah kualitas di Desa Waringinsari, kemudian keadaan sarana transportasi (keadaan jalan) untuk menuju lokasi kebun belimbing tidak begitu mulus karena belum adanya perbaikan jalan untuk menuju lokasi tersebut.
\end{abstract}

Kata kunci : buah belimbing, permintaan, presepsi

\begin{abstract}
This study aims to determine 1) Consumer perceptions of star fruit in Waringinsari Village, Langensari District in Banjar City. 2) Consumer perceptions of the price of starfruit in Waringinsari Village, Langensari District, Banjar City. 3) Consumer perceptions of star fruit promotion in Waringinsari Village, Langensari District, Banjar City. The type of research used is qualitative with a survey method. The sampling technique uses Accidental Sampling. According to Sugiyono (2009), Accidental Sampling is a sampling technique based on chance, that is, consumers who accidentally / incidentally meet with researchers can be used as a sample with 40 respondents. The results showed that the level of consumer influence in the purchase decision of star fruit in Waringinsari village was classified into the medium category. The level of influence when viewed per dimension, namely: a). Product dimensions have a good degree of influence. $b$ ). The price dimension has a moderate level of influence. c). The promotion dimension has a moderate level of influence. The obstacles faced in carrying out the decision-making activities for buying belimbng in Waringinsari Village are: a).
\end{abstract}


Internal constraints; The obstacles faced by respondents in making star fruit purchasing decisions in Waringinsari Village are seen from the internal aspect due to the learning experience and memory in buying star fruit, where the price dimension is an obstacle, because the price is not much different from the price of star fruit in traditional markets, but consumers who buy it Waringinsari Village will get free all you can eat starfruit in the garden with the condition that it is eaten on-site (in the star fruit garden), but with a large star fruit size, so that consumers don't spend much star fruit in the star fruit garden in Waringinsari Village. b) External Constraints; The constraints in purchasing decisions seen from the external aspect are due to social factors, namely the reference group and family. A small proportion of respondents said that they received information through their families and even relatives about the reference to buying star fruit, namely in the traditional market, on the grounds that the price is cheaper even though the product is below quality in Waringinsari Village, then the state of transportation (road conditions) to get to the location of the star fruit garden. not so smooth because there is no road repair to get to that location.

Key words: star fruit, demand, perception

\section{PENDAHULUAN}

Buah merupakan salah satu komoditas holtikultura yang memegang peranan penting bagi pembangunan pertanian di Indonesia. Fungsi buahbuahan sangat penting bagi proses metabolisme tubuh karena mengandung banyak vitamin dan mineral. Dewasa ini, masyarakat mulai memperhatikan untuk mengkonsumsi buah- buahan yang banyak mengandung zat gizi. Hal ini berarti buahbuahan memiliki prospek cerah untuk dikembangkan di Indonesia (Poerwono, 2012).

Seiring dengan perkembangan dan kemajuan zaman, pola pikir masyarakat dalam konsumsi pun ikut berkembang. Pola konsumsi masyarakat Indonesia secara perlahan mengalami perubahan dengan meningkatkan konsumsi pangan yang bernilai tinggi dan mengurangi konsumsi pangan sumber karbohidrat seperti padi dan umbi-umbian. Konsumsi buah-buahan di Indonesia pada dasarnya sudah meningkat sebesar 8,21 persen dari sebelumnya $31,93 \mathrm{~kg} / \mathrm{kapita} /$ tahun pada tahun 2010 menjadi sebesar 34,55 $\mathrm{kg} / \mathrm{kapita} /$ tahun pada tahun 2011. Namun angka tersebut masih jauh di bawah standar konsumsi yang direkomendasikan oleh FAO, yakni sebesar 73 kg/kapita/tahun (Hendriadi 2013).

Permintaan belimbing di Indonesia mengalami peningkatan pada tahun 2018 yang diperkirakan mencapai 16 juta ton/tahun dan kemungkinan terjadi peningkatan pada tahun-tahun selanjutnya. Meningkatnya permintaan akan buah belimbing akan semakin mendorong peningkatan konsumsi buah-buahan di Indonesia (Ginting, 2011).

Desa Waringinsari Kecamatan Langensari Kota Banjar merupakan desa unggulan Kota Banjar di bidang pertanian, 
karena selain potensi sumberdaya pertaniannya, juga masyarakatnya sangat mendukung usaha di bidang pertanian. Semakin tinggi permintaan akan buah belimbing maka semakin banyak faktorfaktor yang mempengaruhinya. Berdasarkan latar belakang tersebut maka sangat menarik untuk melakukan penelitian "Faktor-Faktor Yang Mempengaruhi Perilaku Konsumen Terhadap Permintaan Belimbing Di Desa Waringinsari Kecamatan Langensari Kota Banjar".

\section{Tujuan Penelitian}

Berdasarkan identifikasi masalah tersebut, penelitian ini bertujuan untuk mengetahui:

1. Persepsi konsumen terhadap buah belimbing di Desa Waringinsari Kecamatan Langensari di Kota Banjar.

2. Persepsi konsumen terhadap harga belimbing di Desa Waringinsari Kecamatan Langensari di Kota Banjar.

3. Persepsi konsumen terhadap promosi belimbing di Desa Waringinsari Kecamatan Langensari di Kota Banjar.

\section{METODE PENELITIAN}

\section{Jenis Penelitian}

Jenis penelitian yang digunakan adalah kualitatif dengan metode survei. Menurut Sugiyono (2017) metode survei digunakan untuk mendapatkan data dari tempat tertentu yang alamiah (bukan buatan), tetapi peneliti melakukan perlakuan dalam pengumpulan data, misalnya dengan mengedarkan kuesioner, tes, dan wawancara yang tersetuktur.

\section{Operasionalisasi Variabel}

Untuk memudahkan menyamakan persepsi dengan variabel yang diteliti yaitu sebagai berikut:

1. Permintaan belimbing (Y) adalah jumlah belimbing yang diminta oleh konsumen pada suatu pasar dan diukur dengan satuan $(\mathrm{kg})$.

2. Harga buah belimbing (X1) adalah nilai finansial dari buah belimbing itu sendiri dan diukur dengan satuan rupiah $(\mathrm{Rp})$.

3. Pendapatan konsumen (X2) adalah sumber penghasilan seseorang untuk memenuhi kebutuhannya dan diukur dengan satuan rupiah (Rp).

4. Konsumsi (X3) merupakan sebuah proses pemenuhan kebutuhan akan buah belimbing yang dibutuhkan dan diukur dalam satua kilogram $(\mathrm{Kg})$.

\section{Teknik Pengumpulan Data}

Jenis dan sumber data yang di gunakan dalam penelitian ini adalah data primer dan sekunder. Data primer adalah data yang dikumpulkan dari sumber data pertama (Soekartawi, 2002). Data primer diperoleh melalui survai lapangan dan 
wawancara terhadap petani belimbing di Desa Waringinsari Kecamatan Langensari Kota Banjar. Data sekunder diperoleh melalui studi pustaka yaitu dengan membaca buku-buku yang berkaitan dengan penelitian yang dilakukan, serta dari penelitian-penelitian sebelumnya. Data sekunder juga diperoleh dari Dinas Ketahanan Pangan, Pertanian dan Perikanan Kota Banjar.

\section{Teknik Penentuan Sampel}

Teknik pengambilan sampel menggunakan Accidental Sampling. Menurut sugiyono (2009), Accidental Sampling adalah teknik penentuan sampel berdasarkan kebetulan, yaitu konsumen yang secara kebetulan/insidental bertemu dengan peneliti dapat digunakan sebagai sampel, bila dipandang orang yang kebetulan ditemui itu cocok sebagai sumber data.

\section{Waktu dan Tempat Penelitian}

Penelitian ini akan dilaksanakan di Desa Waringinsari Kecamatan Langensari Kota Banjar. Adapun waktu penelitian ini dilaksanakan pada Bulan Februari 2020 sampai dengan selesai.

\section{HASIL DAN PEMBAHASAN}

\section{Persepsi Konsumen Terhadap Produk}

\section{Buah Belimbing}

Tingkat pengaruh dalam keputusan pembelian belimbing di Desa Waringinsari dinyatakan berdasarkan skor. Kriteria yang digunakan untuk mengetahui tingkat pengaruh konsumen pada keputusan pembelian belimbingdibagi dalam tiga kategori yaitu : 1) baik, 2) sedang dan 3) buruk. Tingkat Presepsi Konsumen Terhadap Produk Buah Belimbing di Desa Waringinsari Kecamatan Langensari Kota Banjar

Produk buah belimbing dapat dikatakan baik dilihat dari warna kulit buah belimbing yang kuning dan matang merata dan siap untuk dipetik dan dinikmati bahkan dapat dinikmanti di lokasi perkebunan belimbing, dikatakan sedang warna kulitnya belum terlalu kuning dan butuh waktu untuk mematangkannya beberapa hari lagi, dikatalkan buruk apabila warna belimbing yang masih hijau dan cenderung masih mentah. Dilihat dari rasa buah belimbing dikatakan baik yaitu rasanya manis alami tanpa pengawet karena matang dipohonnya, dikatakan sedang karena buah belimbing belum matang secara pas, dan dikatakan buruk karena buah belimbing rasanya asam (kecut). Di lihat dari kesegaran buah belimbing dapat dikatakan baik yaitu karena buah belimbing matang dipohonnya dan terlihat kekar (tidak keriput), dikatakan sedang karena kesegaran buah belimbing yang sudah 
terlewat tidak dipetik dan cederung mulai

berwarna kecoklatan, dikatakan buruk dari

segi kesegaran yaitu buah belimbing yang

sudah berwarna kecoklatan dan cenderung

Tabel 1. Tingkat Presepsi Konsumen Terhadap Produk Buah Belimbing di Desa Waringinsari Kecamatan Langensari Kota Banjar

\begin{tabular}{|c|c|c|c|c|c|c|c|}
\hline \multirow{2}{*}{ No } & \multicolumn{6}{|c|}{ Skor Tingkat Pe rse psi Kons umen Pada Indikator Produk } & \multirow{2}{*}{$\begin{array}{c}\text { Tingkat } \\
\text { Persepsi } \\
\end{array}$} \\
\hline & $\mathbf{1}$ & 2 & 3 & 4 & 5 & Jumlah & \\
\hline $\mathbf{1}$ & 3 & 3 & 2 & 3 & 2 & 13 & Baik \\
\hline 2 & 2 & 3 & 2 & 3 & 2 & 12 & Baik \\
\hline 3 & 2 & 3 & 2 & 3 & 2 & 12 & Baik \\
\hline 4 & 2 & 3 & 2 & 3 & 2 & 12 & Baik \\
\hline 5 & 3 & 3 & 3 & 3 & 3 & 15 & Baik \\
\hline 6 & 2 & 3 & 3 & 3 & 2 & 13 & Baik \\
\hline 7 & 2 & 3 & 2 & 3 & 2 & 12 & Baik \\
\hline 8 & 3 & 3 & 3 & 3 & 2 & 14 & Baik \\
\hline 9 & 3 & 3 & 3 & 3 & 3 & 15 & Baik \\
\hline 10 & 3 & 3 & 2 & 3 & 3 & 14 & Baik \\
\hline 11 & 2 & 3 & 2 & 3 & 2 & 12 & Baik \\
\hline 12 & 2 & 3 & 2 & 3 & 2 & 12 & Baik \\
\hline 13 & 3 & 3 & 2 & 3 & 3 & 14 & Baik \\
\hline 14 & 3 & 3 & 2 & 3 & 2 & 13 & Baik \\
\hline 15 & 2 & 3 & 2 & 3 & 3 & 13 & Baik \\
\hline 16 & 2 & 3 & 2 & 3 & 2 & 12 & Baik \\
\hline 17 & 2 & 3 & 2 & 3 & 2 & 12 & Baik \\
\hline 18 & 2 & 3 & 2 & 3 & 3 & 13 & Baik \\
\hline 19 & 2 & 3 & 3 & 3 & 2 & 13 & Baik \\
\hline 20 & 3 & 3 & 3 & 3 & 3 & 15 & Baik \\
\hline 21 & 2 & 3 & 2 & 3 & 3 & 13 & Baik \\
\hline 22 & 3 & 3 & 2 & 3 & 2 & 13 & Baik \\
\hline 23 & 3 & 3 & 2 & 3 & 2 & 13 & Baik \\
\hline 24 & 2 & 3 & 3 & 3 & 3 & 14 & Baik \\
\hline 25 & 2 & 3 & 2 & 3 & 3 & 13 & Baik \\
\hline 26 & 2 & 3 & 2 & 3 & 2 & 12 & Baik \\
\hline 27 & 3 & 3 & 2 & 3 & 3 & 14 & Baik \\
\hline 28 & 3 & 3 & 2 & 3 & 2 & 13 & Baik \\
\hline 29 & 2 & 3 & 2 & 3 & 2 & 12 & Baik \\
\hline 30 & 3 & 3 & 2 & 3 & 2 & 13 & Baik \\
\hline 31 & 3 & 3 & 2 & 3 & 3 & 14 & Baik \\
\hline 32 & 2 & 3 & 2 & 3 & 2 & 12 & Baik \\
\hline 33 & 2 & 3 & 2 & 3 & 2 & 12 & Baik \\
\hline 34 & 3 & 3 & 2 & 3 & 3 & 14 & Baik \\
\hline 35 & 3 & 3 & 2 & 3 & 2 & 13 & Baik \\
\hline 36 & 2 & 3 & 2 & 3 & 3 & 13 & Baik \\
\hline 37 & 2 & 3 & 2 & 3 & 2 & 12 & Baik \\
\hline 38 & 2 & 3 & 2 & 3 & 2 & 12 & Baik \\
\hline 39 & 2 & 3 & 2 & 3 & 3 & 13 & Baik \\
\hline 40 & 2 & 3 & 3 & 3 & 2 & 13 & Baik \\
\hline Jumlah & 96 & 120 & 88 & 120 & 95 & 519 & \\
\hline Rata-rata & 2:04 & 3 & 2:02 & 3 & 2:04 & 0.56736 & Baik \\
\hline
\end{tabular}


Dari Tabel 1 diketahui bahwa ratarata dimensi produk buah belimbing di Desa Waringinsari adalah 0,56736. Hal ini dapat disimpulkan bahwa produk belimbing di Desa Waringinsari memang memiliki pengaruh baik menurut konsumen, itu karena produk buah belimbing di Desa Waringinsari menjualnya dengan cara memetik langsung ke kebun nya, sehingga konsumen dapat memilih buah belimbing yang masih segar dan fresh baik dari segi pemilihan warna kulit, rasa, kesegaran, kandungan gizi dan kebersihan buah belimbing yang mereka inginkan, sehingga kepuasan konsumen terhadap buah belimbing berpresepsi baik. Kandungan gizi yang terkandung pada buah belimbing akan terjaga karena tidak menggunakan zat pengawet maupun pewarna buatan, sedangkan dari segi kebersihan kulit belimbing akan tetap terjada, karena setiap pohon belimbing yang mulai berbuah akan segera di bungkus dengan menggunakan plastik sehingga buah belimbing akan tetap terjada kebersihannya dan akan terhindar dari ulat buah maupun serangan serangga lainnya.

\section{Tingkat Presepsi Konsumen Terhadap Harga Buah Belimbing di Desa Waringinsari Kecamatan Langensari Kota Banjar}

Harga buah belimbing dikatakan baik dilihat dari kesesuaian harga yaitu harga sesuai dengan barang atau produk buah belimbing yang dibayarkan oleh konsumen, dengan cara memetik sendiri dan makan sepuasnya di lokasi perkebunan belimbing, dikatakan sedang yaitu harga yang kurang pas dengan produk produk yang dibayarkan oleh konsumen, dikatakan buruk yaitu harga tidak sama sekai tidak sesuai dengan barang atau produk buah belimbing yang diinginkan oleh konsumen. Dilihat dari tingkat dan keterjangkauan konsumen terhadap buah belimbing yaitu harga yang lebih murah dibandingkan dengan harga yang di tawarkan di pasar tradisional dan swalayan, dikatakan sedang harga nya sebanding dengan harga yang ditawarkan di pasar tradisional dan swalayan, dan dikatakan buruk yaitu harga nya cenderung lebih mahal dari harga yang ditawarkan di pasar tradisional dan swalayan. 
Tabel 2. Tingkat Presepsi Konsumen Terhadap Harga Buah Belimbing di Desa Waringinsari Kecamatan Langensari Kota Banjar

\begin{tabular}{|c|c|c|c|c|c|c|}
\hline \multirow{2}{*}{ No } & \multicolumn{5}{|c|}{ Skor Tingkat Perse psi Kons umen Pada Indikator Harga } & \multirow{2}{*}{ Tingkat Persepsi } \\
\hline & $\mathbf{1}$ & 2 & 3 & 4 & Jumlah & \\
\hline $\mathbf{1}$ & 1 & 2 & 2 & 1 & 6 & Buruk \\
\hline 2 & 2 & 2 & 2 & 1 & 7 & Sedang \\
\hline 3 & 3 & 2 & 2 & 1 & 8 & Sedang \\
\hline 4 & 2 & 2 & 2 & 2 & 8 & Sedang \\
\hline 5 & 2 & 2 & 3 & 2 & 9 & Sedang \\
\hline 6 & 3 & 2 & 3 & 1 & 9 & Sedang \\
\hline 7 & 1 & 2 & 2 & 1 & 6 & Buruk \\
\hline 8 & 3 & 2 & 3 & 1 & 9 & Sedang \\
\hline 9 & 3 & 2 & 2 & 1 & 8 & Sedang \\
\hline 10 & 2 & 2 & 2 & 1 & 7 & Sedang \\
\hline 11 & 2 & 2 & 2 & 1 & 7 & Sedang \\
\hline 12 & 2 & 2 & 2 & 1 & 7 & Sedang \\
\hline 13 & 1 & 2 & 2 & 1 & 6 & Buruk \\
\hline 14 & 3 & 2 & 2 & 1 & 8 & Sedang \\
\hline 15 & 3 & 3 & 2 & 1 & 9 & Sedang \\
\hline 16 & 2 & 3 & 2 & 1 & 8 & Sedang \\
\hline 17 & 2 & 3 & 3 & 1 & 9 & Sedang \\
\hline 18 & 2 & 2 & 3 & 2 & 9 & Sedang \\
\hline 19 & 2 & 2 & 2 & 2 & 8 & Sedang \\
\hline 20 & 3 & 2 & 3 & 2 & 10 & Baik \\
\hline 21 & 3 & 2 & 3 & 2 & 10 & Baik \\
\hline 22 & 2 & 2 & 2 & 1 & 7 & Sedang \\
\hline 23 & 2 & 2 & 3 & 1 & 8 & Sedang \\
\hline 24 & 3 & 2 & 2 & 1 & 8 & Sedang \\
\hline 25 & 2 & 2 & 2 & 1 & 7 & Sedang \\
\hline 26 & 2 & 2 & 3 & 1 & 8 & Sedang \\
\hline 27 & 2 & 2 & 3 & 1 & 8 & Sedang \\
\hline 28 & 3 & 3 & 2 & 1 & 9 & Sedang \\
\hline 29 & 1 & 3 & 2 & 1 & 7 & Sedang \\
\hline 30 & 1 & 3 & 2 & 2 & 8 & Sedang \\
\hline 31 & 2 & 2 & 2 & 1 & 7 & Sedang \\
\hline 32 & 2 & 2 & 2 & 1 & 7 & Sedang \\
\hline 33 & 2 & 2 & 2 & 1 & 7 & Sedang \\
\hline 34 & 1 & 2 & 2 & 1 & 6 & Buruk \\
\hline 35 & 3 & 2 & 2 & 1 & 8 & Sedang \\
\hline 36 & 3 & 3 & 2 & 1 & 9 & Sedang \\
\hline 37 & 2 & 3 & 2 & 1 & 8 & Sedang \\
\hline 38 & 2 & 3 & 3 & 1 & 9 & Sedang \\
\hline 39 & 2 & 2 & 3 & 2 & 9 & Sedang \\
\hline 40 & 2 & 2 & 2 & 2 & 8 & Sedang \\
\hline Jumlah & 86 & 89 & 92 & 49 & 316 & \\
\hline Rata-rata & $2: 15$ & $2: 22$ & 2:04 & $1: 22$ & 7:01 & Sedang \\
\hline
\end{tabular}


Tabel 2 menunjukkan bahwa pada dimensi harga pengaruh konsumen hanya masuk kategori sedang karena pada indikator tertentu seperti potongan harga dan dan keterjangkauan harga buah belimbing, konsumen menganggap hal tersebut masuk kategori sedang, karena harganya tidak berbeda jauh dengan harga belimbing di pasar tradisional, namun konsumen yang membeli ke Desa Waringinsari akan mendapatkan gratis makan buah belimbing sepuasnya yang ada di kebun degan syarat dimakan ditempat (di kebun belimbingnya), akan tetapi dengan ukuran belimbing yang besar, sehingga konsumen tidak banyak menghabiskan belimbing di kebun belimbing di Desa Waringinsari.

\section{Tingkat Presepsi Konsumen Terhadap} Promosi Buah Belimbing di Desa Waringinsari Kecamatan Langensari Kota Banjar

Buah belimbing dikatakan baik dilihat dari promosi yaitu ketika pemilik atau pengurus secara terang-terangan melakukan promosi dengan berbagai cara baik dengan cara online ataupun offline (media cetak, spanduk, brosur, dll), dikatakan sedang yaitu promosi hanya dilakukan oleh pengunjung yang pernah datang ke lokasi perkebunan belimbimg dan mereka memberitahukan kepada teman-teman dan kerabat mereka dari mulut ke mulut, dikatakan buruk yaitu baik pemlilik ataupun pengurus tidak melakukan promosi dengan baik. Dilihat dari ketersediaan buah belimbing dikatakan baik yaitu buah belimbing selalu tersedia sepanjang tahun dan tidak tergantung pada musim, baik musim hujan atau kemarau belimbing tetap tersedia, dikatakan sedang yaitu buah belimbing selalu tersedia namun tidak terlalu banyak, dikatakan buruk yaitu buah belimbing tidak selalu tersedia di setiap tahunnya dan cenderung tidak ada sama sekali. Dilihat dari tenaga penjualnya dapat dikatakan baik yaitu tenaga penjual ramah, mengetahui seluk beluk tentang buah belimbing dan sigap dalam melayani konsumen. Dikatakan sedang yaitu tenaga penjual hanya melayani konsumen saja tanpa mengetahui baik buruk nya buah belimbing yang siap dipetik, dikatakan buruk yaitu tenaga penjual sama sekali tidak melayani konsumen ketika melakukan pemetikan dilokasi perkebunan buah belimbing. Untuk lebih jelasnya dapat dilihat pada Tabel 3. 
Tabel 3. Tingkat Presepsi Konsumen Terhadap Promosi Buah Belimbing di Desa Waringinsari Kecamatan Langensari Kota Banjar

\begin{tabular}{|c|c|c|c|c|c|}
\hline \multirow[b]{2}{*}{ No } & \multicolumn{4}{|c|}{ Skor Tingkat Pers epsi Kons umen Pada Indikator Promosi } & \multirow[b]{2}{*}{ Tingkat Perseps i } \\
\hline & $\mathbf{1}$ & 2 & 3 & Jumlah & \\
\hline $\mathbf{1}$ & 1 & 3 & 2 & 6 & Sedang \\
\hline 2 & 1 & 3 & 2 & 6 & Sedang \\
\hline 3 & 1 & 2 & 2 & 5 & Buruk \\
\hline 4 & 1 & 2 & 2 & 5 & Buruk \\
\hline 5 & 1 & 3 & 2 & 6 & Sedang \\
\hline 6 & 2 & 2 & 3 & 7 & Sedang \\
\hline 7 & 1 & 2 & 3 & 6 & Sedang \\
\hline 8 & 1 & 3 & 3 & 7 & Sedang \\
\hline 9 & 2 & 3 & 2 & 7 & Sedang \\
\hline 10 & 2 & 2 & 3 & 7 & Sedang \\
\hline 11 & 2 & 2 & 3 & 7 & Sedang \\
\hline 12 & 1 & 2 & 3 & 6 & Sedang \\
\hline 13 & 1 & 2 & 2 & 5 & Buruk \\
\hline 14 & 2 & 2 & 2 & 6 & Sedang \\
\hline 15 & 2 & 2 & 2 & 6 & Sedang \\
\hline 16 & 1 & 2 & 3 & 6 & Sedang \\
\hline 17 & 2 & 2 & 3 & 7 & Sedang \\
\hline 18 & 2 & 2 & 3 & 7 & Sedang \\
\hline 19 & 1 & 3 & 3 & 7 & Sedang \\
\hline 20 & 1 & 3 & 3 & 7 & Baik \\
\hline 21 & 1 & 2 & 3 & 6 & Baik \\
\hline 22 & 1 & 2 & 3 & 6 & Sedang \\
\hline 23 & 1 & 3 & 2 & 6 & Sedang \\
\hline 24 & 1 & 2 & 2 & 5 & Buruk \\
\hline 25 & 1 & 3 & 3 & 7 & Sedang \\
\hline 26 & 2 & 2 & 3 & 7 & Sedang \\
\hline 27 & 2 & 3 & 3 & 8 & Baik \\
\hline 28 & 1 & 2 & 2 & 5 & Buruk \\
\hline 29 & 2 & 2 & 2 & 6 & Sedang \\
\hline 30 & 1 & 2 & 2 & 5 & Buruk \\
\hline 31 & 2 & 2 & 3 & 7 & Sedang \\
\hline 32 & 2 & 2 & 3 & 7 & Sedang \\
\hline 33 & 1 & 2 & 3 & 6 & Sedang \\
\hline 34 & 1 & 2 & 2 & 5 & Buruk \\
\hline 35 & 2 & 2 & 2 & 6 & Sedang \\
\hline 36 & 2 & 2 & 2 & 6 & Sedang \\
\hline 37 & 1 & 2 & 3 & 6 & Sedang \\
\hline 38 & 2 & 2 & 3 & 7 & Sedang \\
\hline 39 & 2 & 2 & 3 & 7 & Sedang \\
\hline 40 & 1 & 3 & 3 & 7 & Sedang \\
\hline Jumlah & 57 & 91 & 103 & 251 & \\
\hline Rata-rata & 1.42 & 2.75 & 2.57 & 6.27 & Sedang \\
\hline
\end{tabular}


Tabel 3 menunjukkan bahwa faktor promosi termasuk kedalam kategori tingkat presepsi sedang, karena dilihat dari pelayanan pengurus kebun yang kurang interaktif dalam berkomunikasi dengan konsumen karena pengurus kebun tidak mengerti dan tidak bisa berbahasa sunda sehingga memiliki keterbatasan dalam berbahasa daerah, dan promosi kebun belimbing tersebut belum begitu dikenal oleh masyarakat luas, karena promosi hanya terjadi dari mulut ke mulut para konsumen yang pernah berkunjung dan berbelanja buah belimbing di Desa Waringinsari, namun dari ketersedian buah belimbing di Desa waringinsari tidak pernah kekurangan karena cara penanamannya bertahap tidak bersamaan sehingga berbuahnya belimbing tidak akan bersamaan dan akan tersedia sepanjang tahun.

\section{KESIMPULAN DAN SARAN}

\section{Kesimpulan}

Berdasarkan hasil penelitian dan

pembahasan maka dapat ditarik

kesimpulan :

1. Rata-rata dimensi produk buah belimbing di Desa Waringinsari adalah 0,56736. Hal ini dapat disimpulkan bahwa produk belimbing di Desa Waringinsari memang memiliki pengaruh baik menurut konsumen, itu karena produk buah belimbing di Desa Waringinsari menjualnya dengan cara memetik langsung ke kebun nya, sehingga konsumen dapat memilih buah belimbing yang masih segar dan fresh baik dari segi pemilihan warna kulit, rasa, kesegaran, kandungan gizi dan kebersihan buah belimbing yang mereka inginkan, sehingga kepuasan konsumen terhadap buah belimbing berpresepsi baik.

2. Dimensi harga pengaruh konsumen hanya masuk kategori sedang karena pada indikator tertentu seperti potongan harga dan dan keterjangkauan harga buah belimbing, konsumen menganggap hal tersebut masuk kategori sedang, karena harganya tidak berbeda jauh dengan harga belimbing di pasar tradisional.

3. faktor promosi termasuk kedalam kategori tingkat presepsi sedang, karena dilihat dari pelayanan pengurus kebun yang kurang interaktif dalam berkomunikasi dengan konsumen karena pengurus kebun tidak mengerti dan tidak bisa berbahasa sunda sehingga memiliki keterbatasan dalam berbahasa daerah, dan promosi kebun belimbing tersebut belum begitu dikenal oleh masyarakat luas, karena promosi hanya terjadi dari mulut ke 
mulut para konsumen yang pernah berkunjung dan berbelanja buah belimbing di Desa Waringinsari.

\section{DAFTAR PUSTAKA}

Hendriadi, Agung. 2013. Optimalisasi Kegiatan Litkajibangdiklatluh dan Corporate Management Untuk Peningkatan Kinerja Litbang Hortikultura. Rapat Kerja Pusat Penelitian Pengembangan Hortikultura Badan Penelitian dan Pengembangan Pertanian 26-29 Maret 2013.

Pracoyo, T.K dan A. Pracoyo. 2006. Aspek-Aspek Dasar Ekonomi Mikro. PT Gramedia Widia Sarana Indonesia. Jakarta

Sugiyono. 2017. Metode Penelitian Kuantitatif, Kualitatif, dan $R \& D$. CV. Alfabeta. Bandung.
Teguh, Muhammad. 2005. Metodologi Penelitian EkonomiTeori dan Aplikasi.,PT Raja Grafindo Persada. Jakarta

Utami, P., \& Puspaningtyas, D. E. (2013). The Miracle of Herbs. Jakarta: PT AgroMedia Pustaka.

Marbun, I.I., \& Rahmanta Ginting, E (2014). Analisis Faktor-Faktor Yang Mempengaruhi Perilaku Konsumen Kopi Luwak Bermerek Di Kota Medan. JOURNAL ON SOCIAL ECONOMIC OF AGRICULTURE AND AGGRIBUSSINES, 3(6).

Mizfar,F \& Sinaga, A. (2015). Analisis faktor-faktor yang Mempengaruhi Perilaku Konsumen dalam Pengambilan Keputusan Pembelian Kopi Instan. SEPA : Jurnal social Ekonomi Pertanian dan agribisnis, 11(2), 175-180). 